\title{
O SIGNIFICADO DE CUIDADO PARA PROFISSIONAIS DA EQUIPE DE ENFERMAGEM
}

THE MEANING OF CARE FOR PROFESSIONALS' NURSING TEAM

\section{EL SIGNIFICADO DEL CUIDADO PARA LOS PROFESIONALES DEL EQUIPO DE ENFERMERÍA}

\section{Maria Aparecida Baggio ${ }^{2}$}

RESUMO: Trata-se de um estudo exploratório descritivo de abordagem qualitativa que objetivou compreender o significado de cuidado para profissionais da equipe de enfermagem. Os sujeitos participantes são auxiliares e técnicos em enfermagem e enfermeiros da rede de saúde. Os dados foram coletados por meio de entrevista estruturada e semi-estruturada. A análise de conteúdo foi o método utilizado para análise dos dados. Os resultados permitiram identificar as seguintes categorias de cuidado do outro: o cuidado verbal e não-verbal; a minimização da dor física no cuidado; cuidar com empatia para atender o todo; o envolvimento e o processo de cuidar.

PALAVRAS CHAVES: Assistência ao Paciente; Autocuidado; Equipe de Enfermagem.

ABSTRACT: This is an exploratory and descriptive study grounded in a qualitative approach that aimed to know the meaning of care for professionals' nursing team. The participant subjects are nursing auxiliary and technicians, and health services nurses. The data were collected by structured and semi-structured interview. The analysis of content was the method used to the data analysis. It was possible to identify from the results the following categories of caring the other: the verbal and non-verbal care, the minimization of the physical pain, care with the empathy for to tend the whole, the involvement and the process of care.

KEY WORDS: Patient Care; Self Care; Nursing Team.

RESUMEN: Se trata de un estudio exploratorio descriptivo de abordaje cualitativo con el objetivo de comprender el significado del cuidado para los profesionales del equipo de enfermería. Las personas participantes son auxiliares y técnicos en enfermería y enfermeros de la red de atención en salud. Los datos fueron colectados por medio de entrevista estructurada y semi-estructurada. El análisis del contenido fue el método utilizado para analizar los datos. Por medio de los resultados fuera posible identificar las siguientes categorías de cuidado del otro: el cuidado verbal y no verbal; la minimización del dolor físico en el cuidado; cuidar con empatia para atender el todo; el envolvimiento y el proceso de cuidar.
PALABRAS CLAVES: Atención al Paciente; Auto cuidado; Grupo de Enfermería.
${ }^{1}$ Artigo construído a partir da dissertação de mestrado apresentada à Universidade do Contestado - UnC, Concórdia (SC) intitulada: "O (des)cuidado de si do profissional de enfermagem".

2 Enfermeira, Mestre em Ciências da Saúde Humana pela Universidade do Contestado - UnC, Concórdia (SC). E-mail: mariabaggio@annex.com.br 


\section{INTRODUÇÃO}

O ensino de enfermagem busca capacitar o profissional à prestação de cuidado de saúde ao ser humano-paciente-cliente, à realização e aperfeiçoamento de tecnologias e procedimentos que promovam a saúde, previnam doenças e recuperem lesões; na impossibilidade de cura ou recuperação, favoreça uma morte digna e com o menor sofrimento possível. A este futuro profissional está assegurado um embasamento científico e o desenvolvimento de habilidades técnicas para atender às necessidades do outro, inerentes ao exercício da profissão. O cuidado profissional oferecido está alicerçado na aprendizagem obtida na escola e no exercício da profissão.

Algumas vezes, a educação profissional em nossa sociedade coíbe a criatividade e a individualidade dos alunos, por oferecer-lhes, como alternativa formal, a aquisição passiva de conhecimentos. $O$ processo de formação e capacitação de recursos humanos necessita estar ligado ao desenvolvimento da criticidade do aluno para a habilitação de um profissional ativo e capaz de articular seus pensamentos e idéias. Tal formação deveria estar, igualmente, voltada às necessidades do sujeito enquanto ser humano e, não apenas à técnica, à cientificidade, à competitividade ou a excelência do cuidado prestado.

As propostas pedagógicas das instituições de ensino, particularmente do ensino de enfermagem, são mencionadas como facilitadoras para a aprendizagem sobre o cuidado humano, bastando, para isso, uma reflexão sobre a importância do assunto e adequadas formas de abordagem. Isso porque as pessoas envolvidas nesse processo aprendem e crescem umas com as outras e o processo de cuidar é produto desta interação que, por sua vez, resulta em auto-realização de ambos.

Segundo WALDOW (1998), os docentes das instituições formadoras de profissionais da área de enfermagem até discorrem sobre o cuidado holístico. Porém, tendem a informar aos estudantes conteúdos e conceitos já prontos, enfocando as patologias e os procedimentos técnicos a serem desenvolvidos nas ações de enfermagem e limitando e fragmentando o cuidado, a simples intervenções. Em que momento este aluno é estimulado a refletir sobre o cuidar/cuidado?

Tomando por base uma investigação anterior (dissertação de Mestrado), o presente artigo tem como objetivo compreender o significado de cuidado para os profissionais da equipe de enfermagem que cuida do 'outro' em seu cotidiano. Neste artigo apresentarei alguns significados de cuidado do outro, elucidados pelos profissionais do estudo em questão, indispensáveis para uma prática de cuidado de si mesmo e do outro.

Cabe ressaltar, no entanto, que a discussão sobre a temática não será aprofundada neste artigo, visto que não se constitui no tema central do estudo realizado. Neste momento, a intenção é apresentar alguns resultados obtidos que permitam a reflexão por parte dos leitores.

\section{METODOLOGIA}

Para atender a proposta do estudo foi utilizado o método exploratório descritivo de abordagem qualitativa. Participaram doze profissionais (quatro auxiliares de enfermagem, três técnicos de enfermagem e cinco enfermeiros) que atuam na rede pública e na rede particular no interior do Estado do Rio Grande do Sul e que atuam em diferentes locais como: CAIS (Centro de Atendimento Integrado à Saúde), Postos de Saúde, Hospitais filantrópicos e particulares. Estes foram selecionados aleatoriamente. Para garantir o anonimato os sujeitos foram denominados por nome de flores.

A coleta de dados foi realizada por meio de entrevista estruturada utilizada para caracterizar os sujeitos da pesquisa e, semi-estruturada para conhecer os diferentes posicionamentos individuais sobre o tema de estudo.

As entrevistas foram realizadas após o consentimento dos sujeitos de acordo com a Resolução 196/96. Para o registro dos dados procedeu-se a entrevistas audiogravadas conforme autorização dos entrevistados, posteriormente transcritas e submetidas ao processo de conferência de transcrição.

Os dados coletados foram analisados qualitativamente por meio da leitura e releitura das entrevistas de acordo com a análise de conteúdo, segundo MINAYO (1996).

\section{RESULTADOS E DISCUSSÃO}

O cuidador de enfermagem inserido em uma organização que presta serviço ao 'outro' é responsável pela qualidade do atendimento que é dispensado ao ser cuidado e, para tal, deve empenhar-se e oferecer 0 melhor de si para assegurar um cuidado humanizado (COSTENARO \& LACERDA, 2001).

Indubitavelmente, o exercício do cuidado é uma tarefa difícil e desafiadora. Cuidar, segundo SILVA \& GIMENES (2000, p. 307), "é servir, é oferecer ao outro como forma de serviço, o resultado de nossos talentos, preparos e escolhas", esses adquiridos em nossa vivência de cuidador, demonstrando ao ser cuidado atitudes de cuidado oriundas do nosso conhecimento, afeto e habilidades, as quais, na direção do outro, se transformam em ações que refletem o ser humano que somos e a forma como nos cuidamos.

O ser cuidador, para exercer o cuidado, de acordo com SILVA \& GIMENES (2000), precisa perceber o 'outro' como ele se mostra, nos seus gestos e falas, na sua dor e limitação, pois, por trás de cada situação física de doença, há uma história de 
vida que pode ser percebida em muitos detalhes. Certamente, o corpo físico revela, mesmo que timidamente, muitas informações saudáveis e doentias ali armazenadas.

O ambiente hospitalar é possuidor de características que deixam as pessoas vulneráveis, por ser tenso, sombrio, triste e, às vezes, desalentado. Por sua vez, as pessoas enfermas são submetidas a procedimentos, exames, manipulações que desgastam a si próprios, familiares, amigos e, por que não, a própria equipe que presta os cuidados, principalmente a equipe de enfermagem, que é diretamente responsável pelos cuidados deste ser.

Ao buscar o significado de cuidado, identificado a partir dos discursos dos sujeitos, foi possível identificar os seguintes significados de cuidado do outro.

\section{O cuidado verbal e não-verbal}

$\mathrm{Na}$ perspectiva da enfermagem, cuidar do 'outro' significa atender às suas necessidades com sensibilidade, presteza e solidariedade, mediante ações e atitudes de cuidado realizadas para promover o conforto e o bem-estar. O cuidado manifestado conjuga a integridade física e emocional num processo de troca entre cuidador e ser cuidado.

É possível perceber o cuidado de enfermagem verbal e não-verbal, quando se manifesta por meio da conversa, do toque, com a intencionalidade de transmitir tranqüilidade, carinho, conforto, segurança, atenção e bem-estar, como apontam os depoimentos a seguir:

...Prestar atendimento, tratar muito bem as pessoas que já estão lá, que estão doentes, estão sensíveis elas querem um pouco de atenção ali, que converse [...] não atender assim, mal, sabe [...] (Violeta).

...Tem que atender quando o paciente chama [...] atender bem, de preferência com um sorriso [...] conversar e dar atenção (Camélia).

...É eu transmitir segurança, conforto, bemestar [...] carinho pro paciente [...] (Jasmim).

...Conforto, ta mal deitado, deitar ele direitinho, a posição que ele quer, que fica bem [...] tranqüilizá-lo, conversar (Girassol).

O toque é uma manifestação de cuidado nãoverbal e demonstra preocupação com o 'outro', o cliente. $\mathrm{O}$ ato de tocar aproxima os seres humanos; neste caso, aproxima o cuidador e o ser cuidado. Tulipa, que trabalha em bloco cirúrgico, percebe que o cuidado, por meio do toque, permite sua aproximação com o cliente podendo, neste momento, transmitir-Ihe segurança e conforto, principalmente para os mais idosos, conforme salienta a seguir.

Ao entrar no bloco cirúrgico, o cliente aguarda em uma maca até ser encaminhado à sala cirúrgica para o ato operatório. Percebe, o sujeito, que o cliente que está aguardando até ser encaminhado à referida sala, quando tocado e abordado com carinho e atenção, demonstra sua gratidão pelo olhar e, segundo seu relato, "os olhos deles olham diferente".

\begin{abstract}
...Ah, uma coisa que eu acho muito importante é tocar. Tocar às vezes, assim, tu tem um paciente numa maca ali esperando, pra ir pra sala. Você passa e puxa a coberta e tapa ele, tapa o ombro que está destapado. Como é que você está? Principalmente as pessoas de mais idade. Eu noto assim, parece que o olho deles olha diferente, sabe. Eu acho assim, que às vezes um simples toque dá uma sensação de conforto e de segurança [...] (Tulipa).
\end{abstract}

A tal respeito, BETTINELLI (1998) aponta que o toque, enquanto cuidado, é uma forma de aproximação humana que estimula a sensibilidade e desperta, nas pessoas envolvidas, a possibilidade de troca, reciprocidade e solidariedade na assistência.

Indubitavelmente, Tulipa apresenta sensibilidade e solidariedade em suas atitudes; atitudes estas, que solidificam o sentido do cuidado em enfermagem. Nesse mesmo sentido, COSTA (1998) lembra que uma das características de proximidade física entre o cliente e o cuidador no exercício do cuidado é o toque que, por sua proximidade, favorece o calor humano e o cuidado humanizado.

\section{Minimizando a dor física pelo cuidado}

Ao expressarem os seus valores sobre o cuidado humano, os sujeitos desta pesquisa demonstraram a preocupação em minimizar a dor física apresentada pelo cliente, entendendo tal movimento como manifestação do cuidado. A intenção de aliviar o sofrimento do ser humano que está sob seus cuidados, manter sua dignidade e seus direitos de cidadão nos momentos de fragilidade $e$ dor, denotam o significado do cuidado ao 'outro'.

A administração de drogas para minimizar a dor física, prescrita pelo médico assistente, é uma das funções da enfermagem e, ao mesmo tempo permite, a partir da aproximação do cuidador durante 0 ato de medicar, confortar o paciente que está emocionalmente fragilizado, amenizando suas angústias e medos.

O sofrimento do paciente, causado pela manifestação de algum tipo de dor, provoca desconforto aos profissionais de enfermagem. Contudo, a tecnologia ora existente e a variedade de medicamentos disponíveis tornam possível a minimização do sofrimento, quando a causa é a dor. Os relatos a seguir enfatizam tal situação:

...Fazer técnicas, como a administração de medicamentos, prescritos no caso, pra que ele não sinta dor [...] fazer com que ele não sinta dor, que ele se sinta melhor do que ele está se sentindo no momento que ele tá internado, que ele melhore de saúde (Jasmim). 
Em primeiro lugar aliviar a dor [...] claro que depois vem outros cuidados, exames, coisa e tal...Mas em primeiro lugar é aliviar a dor (Girassol).

Eu acho que tem que atender quando o paciente chama, se pede um calmante, uma coisa assim. Tem que atender rápido e ter os cuidados, necessários para o paciente (Camélia).

\section{Cuidar com empatia para atender o todo}

Há uma grande preocupação dos profissionais de enfermagem em "se colocar no lugar do outro", transmitindo-Ihe o que gostariam de receber se a situação fosse invertida, numa clara atitude de empatia.

Cuidar com empatia, neste estudo, significa entender e compreender o outro como gostaria de ser, também, compreendido, cuidado. Além disso, os cuidadores assumem o cuidado do outro como se fosse o seu próprio cuidado, como apontam os seguintes depoimentos:

...Eu cuido do paciente como eu gostaria que cuidassem de mim, se eu precisasse. Então eu acho que é muito importante a gente cuidar do paciente. Que eu cuido dele como eu gostaria que cuidassem de mim, se eu precisasse (Camélia).

...Acho assim que o que eu tô fazendo ali, o que eu faço pro paciente [...] o que eu tô fazendo pra pessoa eu tô fazendo pra mim mesmo. Eu me sinto bem fazendo isso [...] eu acho o que eu faço pra eles, pra mim é uma coisa boa também [...] (Margarida).

Segundo COSTA (1998), priorizar o cuidado do outro como cuidar de si mesmo implica sentir-se cuidado enquanto cuida, entendendo e compreendendo o outro com empatia; priorizar o outro é um ato de dedicação afetiva. Cuidar com empatia é entender a situação do outro, ver-se no lugar dele e sentir-se em proximidade e igualdade; envolve também atenção às necessidades físicas e psíquicas do ser cuidado.

...É como cuidar, tentar cuidar de si mesmo, né [...] acho que vai cuidar dele pensando como gostaria de ser cuidado, [...] acho que a parte física, a parte psíquica dele, sentimentos, Eu acho que é isso. Ter cuidado da pessoa como se tu tivesse pensando em ti também. Se colocando no lugar dele, entendendo, compreendendo, a empatia. Acho que é isso. Tu se colocar no lugar, daí a empatia em si acho que daí tu vai poder cuidar dessa pessoa (Orquídea).

A relação de empatia é desenvolvida a partir da capacidade de colocar-se no lugar do outro, seja em situações gratificantes ou de frustração. Os seres humanos são singulares e possuem histórias de vida peculiares a si, por isso, nem sempre será possível perceber do mesmo modo. No entanto, a empatia pode ser percebida de modo semelhante, não idêntica, mas próximo, muito próximo do que o outro percebe para si.

...Se colocar no lugar [...] eu imagino assim, tá indo pra um lugar [bloco cirúrgico], tá estressado, porque se tá aí porque está com algum problema de saúde e enxerga todas aquelas pessoas. Aí aquelas pessoas que não estão nem aí pra ti, te botaram pra cima de uma maca e te puxaram pra uma sala, conversando entre eles, rindo e contando piadinhas [...] e tu não sabe quem é quem, é todo mundo igual, com toca, com roupa azul. Eu imagino assim que deve ser uma situação muito desagradável. Como eu trabalho em bloco, Ah! pra nós pegar um paciente, passar pelo corredor e entrar numa sala é uma coisa que a gente faz oitenta vezes por dia [...] agora pra ele [...] (Tulipa).

Em seu relato, Tulipa elucida que se o paciente foi encaminhado até o bloco cirúrgico é porque possui algum problema de saúde e precisa passar por um processo cirúrgico, sendo este um motivo gerador de ansiedade e apreensão. E, ainda, estar inserido neste ambiente é um fator estressante para o paciente uma vez que, tal espaço, é compreendido como um ambiente hostil.

Alguns procedimentos rotineiros do setor exigem manipulação, como colocar o cliente sobre uma maca e transferi-lo para uma sala cirúrgica, desconhecida e fria, com várias pessoas distintas do seu cotidiano, sem saber quem é quem e, tal situação assusta o paciente que a vivencia. Essas pessoas são médicos, enfermeiros, técnicos e auxiliares de enfermagem que formam uma equipe multiprofissional e que irá intervir para realizar o procedimento cirúrgico necessário. Trata-se de um setor diferenciado dos demais e nele se encontram pessoas distintas e, ao mesmo tempo, semelhantes por estarem paramentadas com roupas e toucas iguais e da mesma cor - azul. Saber quem é quem é tarefa difícil ao paciente.

O profissional que trabalha em bloco cirúrgico realiza atividades rotineiras, como, por exemplo, transportar os pacientes da entrada do setor até a sala cirúrgica e, desta, para a sala de recuperação. Assim, pelo depoimento do sujeito: Ah! pra nós pegar um paciente, passar pelo corredor e entrar numa sala é uma coisa que a gente faz oitenta vezes por dia [...] agora pra ele [...], percebe-se a sua sensibilidade em se importar com o possível desconforto do cliente nesta situação, atentando para a possibilidade de tornar a experiência vivida menos desagradável.

É também uma preocupação do sujeito deste estudo a conversa entre os profissionais da equipe que contam piadas e riem entre si neste ambiente 
ocasionando, talvez, uma situação desagradável para o paciente nele inserido.

Sabe-se que o bloco cirúrgico é caracterizado como um ambiente sobremaneira estressante para quem nele se encontra, e não é diferente para os profissionais que ali trabalham, pois o nível de tensão é muito grande. Em função disso, tem-se observado a utilização de mecanismos de defesa pelo trabalhador - individuais e coletivos - para evitar a manifestação ou instalação do estresse individual, desencadeado pelas atividades. A descontração, a piada, o riso são utilizados em determinados momentos para relaxar e liberar a tensão emocional, tanto dos profissionais quanto do paciente que, indubitavelmente, encontrase ansioso e tenso neste meio.

É importante a preocupação expressa no depoimento do sujeito com o 'colocar-se no lugar do outro', imaginando o quanto pode ser desagradável ao paciente enfrentar um ambiente com tais características e atitudes dos profissionais que atuam neste contexto.

A preocupação do profissional de enfermagem estende-se, também, ao distanciamento físico entre o paciente e o seu familiar, pois a estes não é permitido o acesso no bloco cirúrgico. Neste caso, o cuidado é estendido para além das paredes que separam os ambientes interno e externo de tal bloco, por meio da ação cuidativa do profissional de enfermagem que se torna o elo entre o paciente e seu familiar, como se pode observar no relato a seguir:

\begin{abstract}
...A família já não pode entrar, tem que ficar no lado de fora [...] às vezes também, chega alguém [familiar do paciente] na janela [do bloco cirúrgico] e diz assim: Ah! eu gostaria de saber como tá o fulano de tal, ele veio fazer uma cirurgia. Aí, ah! ele já tá na sala, mas você não pode mais ver ele [profissional de enfermagem]. Bah!, mas é que eu não pude chegar a tempo de ver ele antes da cirurgia, [familiar do paciente]. Então eu vejo assim, ó seu Antonio, [paciente], sua esposa chegou agora, gostaria de ver o senhor, mas o senhor não tem como sair da sala [sala cirúrgica], fica tranqüilo, ela tá aí fora, ela perguntou como o senhor tá e ela vai ficar aguardando aí [profissional de enfermagem informa o paciente]. Eu sei que é coisa minha assim, mas eu sinto que o paciente, que o cliente, ele, dá uma sensação de segurança, assim, de não estar abandonado. Eu acho legal [...] (Tulipa).
\end{abstract}

A atitude de cuidado de enfermagem demonstra solidariedade e sensibilidade ao outro; denota preocupação com a integridade moral e dignidade do paciente como ser humano que é; demonstra consideração pelos aspectos não somente físicos, mas também os aspectos psíquicos do ser humano. O profissional de enfermagem, durante a realização do cuidado, busca um atendimento mais humano, considerando, igualmente, que o outro é um ser individual e único, como lembra o sujeito:

O que é cuidar do outro? É ver essa pessoa, esse cliente, como uma pessoa, como alguém que tá precisando não só de um cuidado físico, mas também o lado psicológico, né. Eu imagino assim: ir num lugar que tu nunca foi antes, ser atendido por pessoas que tu não conhece e aquela coisa, que tu às vezes eu comento, mas olha pro paciente, diz bom dia, chama pelo nome, é porque pra nós é uma coisa natural. Às vezes eu imagino assim, que nem esses dias numa reunião eu disse assim: digamos que vocês vão pra um país estranho, aonde você não sabe se vai pela direita, pela esquerda, tu não sabe como se dirigir, e tu fica perdido e as pessoas passam por ti e ninguém te dá bola, passa por ti e assim... [...] então deve dar uma sensação de desespero, né, de insegurança. Eu acho que cuidar do outro, é se preocupar com o físico e também com o psicológico das pessoas. Então eu acho que cuidar é se preocupar com um todo, ver o paciente como um todo, né? (Tulipa).

O cuidado está vinculado ao cuidar também com ação de prevenção. A preocupação do profissional de enfermagem necessita abranger não apenas o biológico, mas a totalidade que permeia 0 cuidado holístico. Conforme COSTENARO \& LACERDA (2001), o profissional de enfermagem não pode limitar a sua atenção ao atendimento daquilo que é visível no corpo. Ampliar a sua visão para o todo é uma necessidade.

O cuidado assumido pelos profissionais não deve focalizar a atenção somente no procedimento que está sendo realizado mas, sobretudo, precisa buscar toda e qualquer possibilidade de inserir o cuidado para promover uma melhor qualidade de sua vida ao outro, uma vez que o princípio norteador das ações de enfermagem é a educação do cliente e a sua compreensão sobre a importância da prevenção.

A orientação prestada pelo profissional de enfermagem visa adequá-la às necessidades do cliente, manifestadas ou não, pois cuidar envolve atender as carências do outro, percebidas pelo profissional de enfermagem, além daquelas referidas pelo paciente no momento da ação cuidativa. Para BETTINELLI (1998, p. 39) "o profissional de enfermagem deve ter a capacidade de utilizar a intuição e ter uma percepção bastante acurada para poder envolver-se mais durante o cuidado [...]".

Um cuidado adequado às necessidades do cliente exige do profissional, como já apontado, a capacidade de perceber e identificar as necessidades do outro, sendo estes atributos advindos da experiência e prática constante no exercício da enfermagem. Quanto mais acurada for a percepção do profissional tanto mais poderá prestar o cuidado de acordo com as peculiaridades e singularidades de 
cada indivíduo. A interação é o elo entre o cuidador e o ser cuidado e que permite, ao primeiro, a percepção e a identificação das necessidades do segundo. É o que sugere o relato a seguir:

Cuidar do outro eu penso assim que é cuidar de uma forma integral, né [...] no sentido de prevenção. E aqui no setor onde eu trabalho, a gente trabalha com vacinas... Desde uma criança recém-nascida com o teste do pezinho, as primeiras vacinas até [...] não tem limite de idade. Então a gente vê a importância de prevenir a doença e não tratar [...] é mais a nível de consultas de rotina. Mas a gente percebe assim a questão do atendimento integral. Então aquela coisa, não só chegar e aplicar uma vacina, mas tu vê a pessoa assim como ser humano, né. Tu vê todas as condições dela, tu dá orientação. Tem que perguntar se a mãe tá amamentando direitinho, se o bebê tá mamando bem, se ela tá tendo alguma dificuldade, daí tu vai orientar a amamentação. Tu vê a questão da higiene, se aquela criança tá sendo bem cuidada, bem alimentada, cuidados com a desnutrição. Às vezes a gente percebe que a mãe não sabe o que fazer com a criança. Então a gente já aproveita e orienta, né. Porque não é somente tu aplicar uma vacina, tu vê, acho, o todo, né. Então eu acho que é principalmente tu não vê, assim, o recém-nascido só doente na tua frente, mas tu vê a pessoa como um todo. Tu vê todas as coisas que possam, que tu possa orientar pra ela [...] pra melhorar a qualidade de vida (Helicônia).

O cuidado de enfermagem é uma continuidade e deve ter envolvimento e ajuda de toda equipe para concretizar um trabalho conjunto entre os profissionais. Para tanto, é imprescindível transmitir ao colega que sucede no atendimento algo percebido como importante e que não foi possível realizar pelo paciente no momento anterior. Assim, entendo que todos os profissionais da enfermagem precisam contribuir com informações para a implementação dos cuidados, realizando um verdadeiro cuidado em equipe, como lembra Lírio:

Cuidar do cliente é atender todas as necessidades que eu percebo ou que ele me refere. Porque, às vezes, o cliente não pode falar ou gesticular o que ele tá precisando, mas eu tenho que observar e tenho que perceber o mínimo que ele tá precisando e tentar ajudar, cuidar [...] dirigir uma palavra ou uma higiene [...] tentar ajudar. Ajudar a cuidar o outro é atender as necessidades que ele tá sentindo naquele momento que eu tô presente [...] no meu turno de trabalho, por exemplo, ou até passar pra alguma colega alguma coisa que eu percebo e que eu não posso fazer no
momento.

Cuidar é suprir necessidades do outro de acordo com o seu estágio de desenvolvimento e a situação que se encontra. Cuidar de uma criança hospitalizada num setor cuja permanência da mãe e do pai é, ainda, restrita devido ao controle de infecção hospitalar, sensibiliza os profissionais que tentam oferecer a essas crianças um cuidado integral. O profissional identifica as necessidades de cuidado do outro e verifica os meios disponíveis para supri-los com afetividade, conforme aponta o sujeito a seguir:

...Bom eu percebo que no meu setor [CTI pediátrica] são desde o entretenimento, uma TV que faça uma diferença para as crianças, brinquedos, carinho, atenção, toda dedicação, até em dar a dieta, o banho, tudo isso. Eu entendo que faz parte do cuidado. Acho bem mais importante essa atenção de suprir essas necessidades, tipo a falta da mãe, a diferença do ambiente que eles estranham bastante, assim, pessoas desconhecidas. Tentar ficar mais próxima das crianças que já tenham entendimento disso, né? Eu entendo que de certa forma, suprir todas as necessidades do outro tanto em todos os aspectos biopsicosocial. Pra mim é isso (Bromélia).

O profissional de enfermagem busca, nas suas ações, auxiliar o ser humano que está hospitalizado a superar as dificuldades encontradas, promovendo a presença, o bem-estar e a recuperação da sua saúde e utiliza-se de recursos disponíveis para suprir as necessidades biopsicossociais deste ser, como lembra Ipê:

Ajudar nos cuidados que eles não têm, que eles não têm condições de fazer por eles mesmos, né. Isso é cuidado [...] cuidado, orientação, pra que ele aprenda se cuidar também. Cuidar dele no que ele não tem condições de fazer por ele mesmo, ajudar ele na auto-estima, educar ele pra que ele aprenda também a se cuidar.

Cuidar é também ajudar o outro a cuidar-se, orientar, educar, ajudar na melhora da auto-estima do cliente que se encontra em uma situação de fragilidade; é ajudar o outro a satisfazer as suas necessidades e cuidados próprios; é assegurar que o ser cuidado obtenha o máximo de bem-estar possível, de acordo com as suas condições/possibilidades, já que, segundo Rosa,

...Cuidar do outro eu acho que é dar atenção, escutar, orientar, ouvir. O cuidado propriamente dito. Que seria, esse paciente vem te procurar pra quê? Pra um curativo? Então você faz o curativo, pode conversar com 
ele. Muitas coisas se resolvem ali. Orientar [...] uma mãe que vem fazer uma vacina no filho, pergunta mil e uma coisa. Você vai orientando, vai conversando. Quantos filhos ainda tem? Se eles são vacinados? Tu vai perguntando. É cuidar do outro. Pra mim é um cuidado.

Cuidar solidariamente, segundo BETTINELLI (1998), significa ter atitudes, executar técnicas e procedimentos, mantendo um diálogo educativo de forma a intensificar a relação entre o ser cuidado e o cuidador.

\section{O envolvimento e o processo de cuidar}

Violeta que é cuidadora e pôde experienciar uma situação, em que precisou ser cuidada pelo colega e profissional de enfermagem, afirma que cuidado é mais do que administrar uma medicação, é presença, atenção, diálogo, é fazer sentir-se bem; cuidar é ter paciência e confortar o outro, pois nenhuma medicação tem o efeito de confortar, acarinhar ou dar atenção. Contudo, a confiança entre os sujeitos envolvidos (cliente e profissional) é um imperativo essencial para a consolidação do cuidado, como lembra Violeta:

...Eu já fiquei doente [...] tava ruim, me senti sozinha, mal assim sabe. Ninguém foi lá me ver. E tinha as gurias, a Fulana [auxiliar de enfermagem e colega] me atendeu super bem, foi lá conversou comigo. Aquilo lá foi além da medicação, sabe, além da medicação, foi lá conversou comigo que eu tava ruim. Ficou lá e fez eu me sentir bem. Eu acho que é isso o cuidado da pessoa. Além de dar a medicação, tem que, sei lá, tem que ter um [pausa] ah! [pausa] como é que eu vou te explicar [pausa] tem que tratar bem, tem que tratar bem. Eu tava ruim aquele dia, tava ruim, era tudo junto. Eu tava com um medo, um medo, de medicação na veia. A Fulana veio e disse: calma Violeta, calma, tu vai se sentir melhor, não sei o que e conversando, sabe, eu já fui me esquecendo daquilo. Tem que ter paciência. Na hora tu não tem paciência, quer que passe, tava com uma dor de cabeça horrível, uma náusea horrível, tava ruim, tava me sentindo ruim, mal-estar. Ela foi lá conversou comigo, disse: ó, tu dorme, tu descansa, qualquer coisa que tu não tiver se sentindo bem tu pega e tu me chama, sabe. Chega e já conversa contigo sabe, faz tu se sentir à vontade, bem, se sentir bem.

Num passado não muito distante, o envolvimento da enfermagem com o paciente era evitado, contra-indicado, não estimulado. O profissional não deveria se envolver com o paciente, sendo que, os próprios colegas alertavam: 'olha o envolvimento!'. Atualmente se questiona a atitude de 'não envolvimento', pois se preconiza que, para haver um cuidado humanizado e adequado ao outro ser é necessário que ocorra a empatia, a afetividade, o envolvimento, a aproximação entre o cuidador e o ser cuidado com a finalidade terapêutica, não limitada à simples execução de técnicas ou cumprimento das atividades concernentes à enfermagem.

WALDOW (1998) considera o cuidar não apenas como uma tarefa a ser executada no sentido de tratar uma ferida ou auxiliar na cura de uma doença e, sim, num sentido mais amplo como um cuidado por meio do 'relacionamento com o outro, como uma expressão de interesse e carinho'.

Quem cuida do outro em seu cotidiano está susceptível a vivenciar também sentimentos desagradáveis que lhe causam sofrimento, principalmente, quando o vivenciado é a morte. A enfermagem é uma das profissões em que ocorre um grande desgaste emocional do trabalhador devido à constante interação com seres enfermos, muitas vezes, acompanhando o sofrimento, como a dor, a doença e a morte do ser cuidado.

É possível cuidar sem envolvimento? É possível não se apegar, não se envolver, principalmente quando o ser cuidado é uma criança? Margarida afirma que tenta não se apegar porque Ihe faz mal experienciar a perda do outro, seja na alta hospitalar seja na própria morte. Mas é possível evitar o apego e a dor da perda quando cuidamos?

Alguns profissionais interpõem barreiras na relação de cuidado, alegando o não envolvimento como necessário para evitar o sofrimento limitando, dessa forma, a atitude de cuidar. Devido a situações de sofrimento, frente ao sentimento de perda do outro, o profissional busca alguns mecanismos de defesa individual para não sofrer constantemente a cada situação vivenciada. Em muitos casos, se esses mecanismos não forem utilizados, o profissional se tornará incapaz de desenvolver suas atividades.

Em seus estudos, PITTA (1999), assinala alguns mecanismos de defesa, sendo a fragmentação da relação técnico-paciente uma relação na qual o profissional evita um contato muito próximo ao ser cuidado como meio de se defender da própria dor e sofrimento diante de situações críticas, pois o não envolvimento afetivo nessa relação evita o sofrimento com a dor ou a perda do outro. Será possível cuidar do outro sem se envolver? Vejamos o que aponta Margarida:

....No sentido de doença [...] eu não procuro me apegar. Que assim, claro que tu acostuma com o paciente ali, daí tu fica. Mas eu não costumo me apegar assim, porque eu acho que isso não faz bem pra gente [...]. O B., aquele menino que morreu. Aquele ali tu sente, né? Eu senti assim na hora. Só que eu não posso, porque eu acho que isso faz mal pra ti. Eu penso assim, que tu tá aqui pra ajudar, já fazendo o que precisa ajuda, não pode ter pena. 
Entre a equipe multiprofissional, os membros da equipe de enfermagem são os que ficam mais próximos do paciente, pois trabalham mais diretamente na sua prestação de cuidados. Alguns pacientes ficam vários dias, vários meses internados na mesma unidade. É possível não se apegar, não se envolver durante a convivência?

BETTINELLI (1998) aponta que alguns profissionais de enfermagem na relação de cuidado demonstram um envolvimento com o paciente bastante superficial, supervalorizando os aspectos científicos, as rotinas, os problemas burocráticoadministrativos, as normatizações de técnicas e de procedimentos. Estas atitudes denotam a impessoalidade do cuidador, sendo a intuição, o envolvimento, a sensibilidade e a solidariedade substituída pelo mero cumprimento de tarefas rotineiras, fazendo com que a relação com o paciente se torne fragmentada, fria, simplificada e, às vezes, distante, transformando o ser humano em um objeto do cuidado.

O autor considera que a visão tecnicista do profissional de enfermagem pode afastá-lo cada vez mais do ser cuidado e ainda, impedir as reflexões sobre sua postura e conduta profissional, podendo tornar-se antiética.

\section{CONCLUSÃO}

A prática do cuidado pelo profissional de enfermagem, objetiva prioritariamente cuidar do outro, direcionando a atitude cuidativa para o ser que está sob os seus cuidados. O cuidar do outro, pelas trocas que proporciona, traz para o cuidador sentimentos de prazer e satisfação, ou seja, cuidar do outro é também cuidar de si mesmo.

Evidencia-se o cuidado do outro pelo profissional de enfermagem de maneira verbal e nãoverbal, atendendo os aspectos físico e emocional, de modo a preservar a dignidade de ser humano que é. A dor manifestada pelo outro sensibiliza o profissional, que busca em suas ações o seu alívio, mediante atitudes de empatia na prática cuidativa.

O 'envolvimento' no cuidado de enfermagem é apontado como indispensável para cuidar como medida de aproximação entre o cuidador e o ser cuidado com finalidade terapêutica.

\section{REFERÊNCIAS BIBLIOGRÁFICAS}

BETTINELLI, L.A. Cuidado Solidário. Passo FundoRS: Pe. Berthier, 1998.

COSTA, A.L.R.C. O cuidado como trabalho e o cuidado de si no trabalho de enfermagem. 1998. 150p. Dissertação (Mestrado). Pós Graduação em Enfermagem da Universidade Federal de Santa Catarina / Universidade Federal do Mato Grosso. Florianópolis (SC).
COSTENARO, R.G.S.; LACERDA, M.R. Quem cuida de quem cuida? Quem cuida do cuidador? Santa Maria: Unifra, 2001.

MINAYO, M.C.S. O desafio do conhecimento: pesquisa qualitativa em saúde. 4. ed. São Paulo: Hucitec/Abrasco, 1996.

PITTA, A. Hospital dor e morte como oficio. 4. ed. São Paulo: Hucitec, 1999.

SILVA, M.J.P.; GIMENES, O.M.P.V. Eu - o cuidador. Rev. O mundo da saúde, São Paulo, ano 24, v. 24, n. 4, p. 307-309, 2000.

WALDOW, V.R. Cuidado humano: o resgate necessário. Porto Alegre: Sagra Luzzatto, 1998.

WALDOW, V.R. Cogitando sobre o cuidado humano. Cogitare Enferm., Curitiba, v. 3, n. 2, p. 7-10. 1998.

Texto recebido em 07/03/2006

Aprovado para publicação em 30/04/2006 